https://helda.helsinki.fi

\title{
Reassessing The Case Against Evidential Externalism
}

\section{Fratantonio, Giada}

Cambridge University Press

2018

Fratantonio, G \& McGlynn , A 2018 , Reassessing The Case Against Evidential Externalism . in V Mitova (ed.), The Factive Turn in Epistemology . Cambridge University Press, Cambridge, pp. 84-101.

http://hdl.handle.net/10138/266785

draft

Downloaded from Helda, University of Helsinki institutional repository.

This is an electronic reprint of the original article.

This reprint may differ from the original in pagination and typographic detail.

Please cite the original version. 


\author{
Reassessing the Case Against Evidential Externalism \\ Giada Fratantonio and Aidan McGlynn \\ Forthcoming in The Factive Turn in Epistemology, ed. Veli Mitova, CUP \\ [pre-copy edited edition; please cite final version where possible]
}

\begin{abstract}
This paper reassesses the case against Evidential Externalism, the thesis that one's evidence fails to supervene on one's non-factive mental states, focusing on two objections to Externalism due by Nicholas Silins: the armchair access argument and the supervenience argument. It also examines Silins's attempt to undermine the force of one major source of motivation for Externalism, namely that the rival Internalist picture of evidence is implicated in some central arguments for scepticism. While Silins concludes that the case against Evidential Externalism is surprisingly strong, reassessing the arguments supports the opposite conclusion; the objections to Externalism are weak, and for all Silins has shown it may well have unmatched advantages when it comes to resisting scepticism.
\end{abstract}

\title{
1. Introduction
}

Let internal twins share 'the same non-factive mental states to the same degree - the same beliefs, apparent experiences, apparent memories, and so on' (Silins 2005: 3767). We can then ask: must internal twins have the same evidence as each other? Following Nicholas Silins, we'll call an affirmative answer to this question Evidential Internalism and a negative answer Evidential Externalism.

Evidential Externalism is not equivalent to the thesis that evidence is factive. One can consistently hold that evidence must be true and that evidence must be shared by internal twins if one holds that one's evidence consists of true propositions about how things seem to one, for example. So accepting factivity does not suffice to make one an Evidential Externalist. Accepting factivity isn't necessary either. For example, one might hold that one's evidence is just what one is non-inferentially justified in believing and have a reliabilist conception of what such justification requires (e.g. Goldman 2009); on such a view, one's evidence can in principle contain falsehoods, but external differences can make for differences in what evidence twins possess.

Nor is Evidential Externalism to be equated with the thesis that in epistemically favourable cases, one can have entailing evidence for propositions about one's external environment: evidence that entails the truth of the proposition it is evidence for. ${ }^{1}$ Again, we can demonstrate the point with appeal to reliabilism; I may not share the same evidence as my internal twin due to differences in our external environments giving rise to differences in the reliability of the methods we each use, but it may additionally be that the best that either of us can hope for is to have evidence for propositions about our environment that makes them very likely to be true without entailing their truth (compare Silins 2005: 399-400 n11). That duly noted, the kind of Evidential Externalism that will be our focus here does accept that epistemically successful subjects will have entailing evidence lacked by their less successful internal

\footnotetext{
${ }^{1}$ Note that, in contrast to the conventions we adopt here, the claim that evidence is entailing in this sense is sometimes labelled factivity; see, for example, Pritchard 2012.
} 
twins; Silins calls this variety of Evidential Externalism Entailing Evidence Externalism. It is in this sense, then, that we are engaged with the factive turn in epistemology.

Why should epistemologists care about the debate between Evidential Internalists and Evidential Externalists? A first reason is that Evidential Internalism is sometimes thought to be implicated in central sceptical arguments (Williamson 2000: ch 8; Silins 2005: 375-6); crudely put, if my evidence for propositions about my external environment can be no better than that of my internal twin who's just a brain in a vat, then it's hard to see how I can have knowledge on that basis. A second reason, suggested by Silins, is that there may be advantages in casting the opposition between Internalism and Externalism in terms of evidence. In particular, Silins notes that Evidential Externalism articulates an externalist position in epistemology that may side-step some standard worries about reliabilism, at least in the non-reliablist versions we're focusing on (2005: 378-9), and there may be similar advantages for internalists too. If that's right, then perhaps recasting the internalism/externalism debate might enable us to move past the longstanding impasse, or at the very least might let us approach it from a fresh angle. ${ }^{2}$ Finally, one might be interested in the prospects of a particular version of Evidential Externalism, which will naturally lead one to investigate whether there are any objections that are effective against such externalist views in general (McGlynn 2014: 67).

For at least these reasons, epistemologists should be interested in the debate between Evidential Internalists and Externalists. And in an influential 2005 paper, Nicholas Silins first framed the opposition as we have presented it above, and he offered an overarching assessment of the case for Evidential Internalism. Surprisingly, he concluded that even those sympathetic to Externalism need to acknowledge that there's a strong case for Internalism to be answered. In this paper, we offer a reassessment, focusing on the same key arguments that Silins considered-which remain the key arguments against Externalism in general ${ }^{3}$ - but concluding that to the extent that he has correctly identified the strongest motivations for Evidential Internalism, the case in its favour is weak.

The standard ways to try to mount an attack on evidential externalism start from premises about the kind of privileged access we enjoy to our own evidence: for example, the premise that one's own evidence is transparent to one, in the sense that one is normally in a position to know whether something is or isn't part of one's evidence, or that one can sometimes know what one's evidence is 'from the armchair'. Silins takes such arguments to be limited; in section 2 we offer an overview that essentially concurs with his verdict here. The strongest argument against Evidential Externalism, Silins suggests, doesn't make a play with the idea that one has privileged access to one's evidence at all; rather, it pays careful attention to the way in which endorsing Evidential Externalism gives rise to counterexamples to the thesis that internal twins are equally justified. We examine this argument in section 3 , concluding that it is a failure. Finally, in section 4 we turn our attention to scepticism. As already noted, Evidential Internalism has implicated in standard sceptical arguments, and so

\footnotetext{
${ }^{2}$ For an excellent overview of the general internalism/externalism debate about justification, see Littlejohn 2012: ch 1.

${ }^{3}$ Other objections have been proposed to specific varieties of Evidential Externalism, but we leave those more narrowly targeted arguments aside here; see Pritchard 2012 and McGlynn 2014: chapter 4 for relevant discussion.
} 
some have naturally drawn the conclusion that Externalists are better placed when it comes to resisting sceptical conclusions. Silins argues that this tempting conclusion is incorrect; Internalism is at least well positioned to resist scepticism, if not better positioned. We argue that Silins's argument for this is also unsuccessful, thereby completing our argument that Silins has failed to build a strong case for Evidential Internalism.

\section{Access Arguments}

As noted in the introduction, arguments for Evidential Internalism have tended to try to show that it is entailed by a thesis about the nature of our access to our own evidence. Silins considers two access arguments. The first is an argument grounded on the following transparency thesis:

(Transparency): For any proposition $\mathrm{P}$, if one is suitably alert and conceptually sophisticated, then one is in a position to know whether or not one's evidence includes P. (2005: 380)

Let's suppose that Gary is in the good case - he's mistaken about a few things, but mostly he's pretty epistemically successful - and let's contrast Gary with his internal twin Barry who is in the bad case; he's 'a radically deceived brain in a vat, as deceived as can be given that he has the same non-factive mental states as Gary' (2005: 375). Now, according to this first access argument, if both Transparency and Evidential Externalism are true, then Barry could be in a position to know that he is in the bad case. That's because a suitably reflective subject like Barry can figure out that if Evidential Externalism is right, then he's only in the good case if he has entailing evidence: for example, if his evidence for some proposition $\mathrm{P}$ includes $\mathrm{P}$ itself (Williamson 2000), or that he sees that P (Pritchard 2012), say. And given Transparency, he's in a position to know that he doesn't have any such evidence, allowing him to correctly infer that he's in the bad case. But subjects in the bad case aren't in a position to know that they are; as Williamson memorably puts the point, '[p]art of the badness of the bad case is that one cannot know how bad one's case is' (2000: 165). Defenders of Transparency thus take this argument to show that that Evidential Externalism is false and Evidential Internalism is true.

However, Silins concedes that this does not constitute a serious objection to evidential externalism, since it relies on questionable assumptions. In particular, Silins points out that Williamson has a well-known argument, the anti-luminosity argument, which he takes to show that Transparency is false. ${ }^{4}$ The upshot is that if this is the only argument in favour of Evidential Internalist, as Williamson seems to suggest (2000: 172-3), then the motivations for the view look at best questionable.

Crucially, Silins argues that contrary to what Williamson suggests, the case for Evidential Internalism need not make any play with Transparency. In particular, he constructs a novel access argument in favour of Internalism which does not rely on as strong an access thesis as Transparency. In the remainder of this section, we'll consider Silins' novel access argument, and we'll argue (in line with Silins's own

\footnotetext{
${ }^{4}$ See Williamson 2000: chapter 4, and see McGlynn 2014: chapter 7 for an overview of the argument and the subsequent literature on it.
} 
conclusion) that it ultimately fares not much better than the argument from Transparency.

Instead of starting from Transparency, Silins's new access argument relies on the following thesis:

(Armchair Access): It is sometimes the case that: one's evidence includes some proposition E, and one knows from the armchair that one's evidence includes E. (Silins, 2005: 381)

Silins takes armchair knowledge to be knowledge that 'does not constitutively depend on one's having had any particular sense experience or type of sense experience' (2005: 380). Now, according to this second access argument against Evidential Externalism, it is false because when we conjoin it with Armchair Access, it leads to unacceptable conclusions about what we can know from the armchair. We'll develop the argument as Silins does by focusing on a particular variety of Evidential Externalism, $\mathrm{E}=\mathrm{K}$, according to which one's total evidence consists of all and only the propositions which ones knows (Williamson 2000: chapter 9), though there will be an analogous problem for other versions of Externalism. ${ }^{5}$

Consider the following scenario. Gary is in a room looking at a dial reading 0.4. Now, recall from above that Gary is in the good case, and so on this basis he has acquired perceptual knowledge that the dial reads 0.4 . It then follows from $\mathrm{E}=\mathrm{K}$ that the proposition that the dial reads 0.4 is part of Gary's evidence. If we have a suitable witness for Armchair Access on our hands here - an issue we'll return to soon - Gary can know that the proposition that the dial reads 0.4 is part of his evidence from his armchair. Furthermore, assuming that $\mathrm{E}=\mathrm{K}$ is true, there seems to be no in principle barrier to Gary knowing this from the armchair, and so knowing in particular that if $\mathrm{P}$ is part of his evidence, then $\mathrm{P}$ is true. But now the Externalist seems to be in trouble. As Silins writes:

$[w]$ e should $[\ldots]$ expect that, if Gary puts the two pieces of armchair knowledge together and infers what they entail, he will also have armchair knowledge of what follows from the two pieces of armchair knowledge.

That is, assuming the truth of a plausible closure principle for armchair knowledge, it follows that Gary is in a position to know from the armchair that the dial reads 0.4. And this seems absurd; it's not possible to know this kind of contingency about one's immediate perceptible environment from the armchair. So if Armchair Access is plausible, Silins's access argument seems to show that Evidential Externalism is false.

Silins himself is reluctant to draw such a strong conclusion. He observes that the argument is parallel to the notorious McKinsey paradox, concerning the incompatibility between Content Externalism and Privileged Access. Let's take Content Externalism to be, roughly, the thesis that the content of our thoughts is determined by factors external to our environment, and Privileged Access to be the

\footnotetext{
${ }^{5}$ See in particular the discussion of the Access Problem for epistemological disjunctivism in Pritchard
} 2012. 
thesis that one can know what one is thinking from the armchair. ${ }^{6}$ The McKinsey paradox (McKinsey 1991) seems to show that Content Externalism and Privileged Access are incompatible, since together they lead to the absurd conclusion that we can know contingent facts about our environments from the armchair. For example, suppose that I am thinking that water is wet. Privileged Access entails that I can know from the armchair that I am thinking that water is wet. Content Externalism entails (let's suppose) that if I have any thoughts about water, then I have interacted with $\mathrm{H}_{2} \mathrm{O}$. Given that the case for Content Externalism rests on a priori philosophical argumentation, it seems that I can come to know that it is true from armchair as well. Given a closure principle for reflective knowledge, it follows that I can have armchair knowledge that I have interacted with $\mathrm{H}_{2} \mathrm{O}$. And this seems absurd.

A number of responses have been offered to this 'paradox' since McKinsey's paper was published, and it's widely accepted that while there's a potential puzzle here for Content Externalism, given the plausibility of Privileged Access, there's not fatal problem in the offering. ${ }^{7}$ And as Silins points out, given the (intentional) similarities between the McKinsey paradox and his access problem for Evidential Externalism, it seems hard to resist drawing a similar conclusion concerning the latter:

Just as the McKinsey argument poses a puzzle for the content externalist, rather than a strong objection to the view, the new access argument poses a puzzle for the evidential externalist, rather than a strong objection to the view. (Silins 2005: 384)

We agree that there's no strong objection here, but in fact, we want to suggest that Silins's argument may not even be as successful against Evidential Externalism as the parallel argument is against Content Externalism. That's because it's not clear to us that Armchair Access really does underwrite the argument Silins presents. As stated, the thesis only says that one is 'sometimes' able to know that one's evidence contains proposition E from the armchair; it's got the force of an existential generalization, and that's what makes the claim seem so plausible. Notice, however, that Silins's argument assumes that we are licensed to pick particular propositions about Gary's environment, such as the proposition that the dial in front of him reads 0.4 , as witnesses to this existential.

Silins is aware that there's an issue here, and he tries to plug the gap in his argument by insisting that it would be ad hoc for the Evidential Externalist to hold that such contingencies about one's external environment can't be witnesses to Armchair Access:

It would be ad hoc for the externalist to accept that we sometimes have armchair access to our evidence, yet insist that we never have armchair access to our environmentally sensitive evidence. After all, it would be ad hoc for a content externalist to say, we have privileged access to some of our mental

\footnotetext{
${ }^{6}$ It is worth mentioning that the notion of Privileged Access, as it appears in McKinsey's papers, is stated in terms of 'a priori' knowledge rather than 'armchair knowledge'. However, since McKinsey and others in this literature intend for 'a priori' knowledge to include knowledge on the basis of introspection, this seems like unfortunate and possibly misleading terminology: see, for example, Nuccetelli 1999, Brown 2004: 23-4, and Farkas 2008: 130 for relevant discussion.

${ }^{7}$ For a useful overview of responses to the paradox, see Kallestrup 2012: ch 5.
} 
states, just not to any of our environmentally sensitive mental states. No such restrictions are built into the plausible thoughts about how we can access our evidence or mental states. (2005: 381)

However, Silins offers nothing in support of this charge of ad hocery. In particular, he doesn't say anything that might reassure us if we're concerned that the only reason Armchair Access seems so plausible as he states it is because when we consider whether there are any witnesses to its existential, we tend to think of unproblematic candidates. It's not clear to us that there is any access thesis that is both plausible and which genuinely underwrites Silins's argument; Armchair Access itself is plausible as stated. Here we find a potential contrast with the McKinsey paradox; the claim that one is typically able to know from the armchair that one is thinking that water is wet both seems extremely plausible and suffices to get the paradox rolling. ${ }^{8}$

To sum up, Silins's novel access argument aims to show that Evidential Externalism and Armchair Access are incompatible, since together they lead to absurd conclusions concerning what we can know from the armchair. Since Armchair Access is plausible, that puts pressure on Evidential Externalism, in the same way as the McKinsey reasoning puts pressure on Content Externalism, to the extent that we find Privileged Access plausible. In this section, we have agreed with Silins that his novel access argument is no more problematic for Evidential Externalism than the McKinsey paradox is for Content Externalism, but we've further contended that Silins may have overstated the incompatibility between Evidential Externalism and Armchair Access ${ }^{9}$.

\section{The Supervenience Argument}

The strongest argument in favour of Evidential Internalism over Externalism, Silins suggests, doesn't make a play with any kind of thesis about our access to our own evidence at all. In this section, we'll lay out Silins's argument and the assumptions it rests on. The target, recall, is evidential externalism:

(Evidential Externalism): It's possible that: A and B are internal twins and A and B do not have the same evidence. (Silins 2005: 378)

Rather than eliciting a clash with any kind of claim about our access to our evidence, Silins's supervenience argument aims to spell out how Evidential Externalism conflicts with the following thesis:

\footnotetext{
${ }^{8}$ It is worth stressing that some versions of Evidential Externalism do accept a more expansive access claim; for example, epistemological disjunctivism, stated in terms of evidence, entails that in paradigm cases of perceptual knowledge, one has entailing and reflectively accessible evidence. So even if the considerations we have offered in this section show that Entailing Evidence Externalism is not in general vulnerable to Silins's access argument, they may leave some varieties of Externalism facing a challenge. Disjunctivists have their own response to that challenge (e.g. Pritchard 2012: 46-52); whether that response is adequate is a topic for another occasion.

${ }^{9}$ In unpublished work, one of us (Fratantonio) puts forward a second response to Silins' Access Argument, one which questions the notion of armchair knowledge involved in the Armchair Access thesis. Interestingly, this second response and the one we have developed here result being compatible and mutually supportive.
} 
(Equal Justification): Necessarily, if $\mathrm{A}$ and $\mathrm{B}$ are internal twins, then $\mathrm{A}$ is justified to degree $n 1$ in believing $P$ to degree $n 2$ just in case $B$ is justified to degree $\mathrm{n} 1$ in believing $\mathrm{P}$ to degree $\mathrm{n} 2$.

As stressed in the introduction, Silins's point isn't just that Evidential Externalism leads to counterexamples to Equal Justification (though he does think that is already a problem), but rather that the counterexamples can take a particular form. While Silins concedes that the Evidential Externalist may welcome the result that the subject in the good case can be more doxastically justified than the subject in the bad case, he thinks that even they will recoil from the conclusion that the subject in the bad case might come out ahead. But that's a consequence of their position, Silins argues, given only assumptions that are very plausible in their own right. These assumptions are as follows:

(Assumption 1): If the probability of $\mathrm{P}$ on one's evidence is $\mathrm{n}$, then one's degree of confidence in $\mathrm{P}$ ought to be $\mathrm{n}$.

(Assumption 2): If one's degree of confidence ought to be $\mathrm{n}$, and one's actual degree of confidence diverges from n, then one's actual degree of confidence is less than fully justified insofar as it diverges from what it ought to be. (Silins 2005: 387) $)^{10}$

So one's degree of confidence that $\mathrm{P}$ ought to match the evidential likelihood of $\mathrm{P}$ for one, and if it doesn't, then one's degree of confidence is less than fully justified. In fact, Silins implicitly appeals to a natural generalisation of Assumption 2, which we'll label Assumption 2':

(Assumption 2') If one's degree of confidence ought to be $n$, and one's actual confidence diverges from $n$, then one's actual degree of confidence is less than fully justified insofar as it diverges from what it ought to be, and is more or less justified depending on how much it diverges from what it ought to be.

We can see why the final, additional clause is needed by examining how Silins argues that Evidential Externalism leads to counterexamples to Equal Justification. For now, we're only concerned with his argument that Evidential Externalism entails that the subject in the good case can be more justified than the subject in the bad case; we'll turn to the more controversial-sounding result shortly.

Suppose that Gary has the proposition that there is a black spider in front of him as part of his evidence. Gary's evidence entails that he's not a brain in a vat being deceived into thinking that there's a black spider in front of him. His internal twin in the bad case, Barry, can't have this as part of his evidence (or so Entailing Evidence Externalism rules), since there isn't a black spider in front of Barry; his evidence will instead include (say) that it appears to him that there's a black spider in front of him. ${ }^{11}$

\footnotetext{
10 While the formulations are taken straight from Silins, the labels are ours.

11 This description of Barry's evidence in the bad case isn't mandated by Evidential Externalism, but it is very natural and it has been suggested by prominent Externalists (e.g. Williamson 2000: 198-9 and Pritchard 2011: 244). Pritchard develops a much more fine-grained taxonomy of good and bad cases in his 2012, and we don't mean to suggest that he would accept this description of the subject's evidence in all the variants of the bad case that he considers.
} 
Since Gary's evidence is entailing, the evidential probability for him that he's not a brain in a vat being deceived into thinking that there's a black spider in front of him is 1. Let us suppose that the evidential probability of that same proposition for Barry is less than .9. ${ }^{12}$ Since Gary and Barry are internal twins, they share the same degrees of confidence, and in particular each is .99 confident that he is not a brain in a vat being deceived into thinking that there's a black spider in front of him. Silins concludes (2005: 388):

The upshot is that one can be more justified in the good case than the bad case, if Evidential Externalism is true.

As promised, we can see the need for Silins to rely on Assumption 2' here, rather than on Assumption 2 as he states it. Silins's own statement only allows us to conclude that neither Barry nor Gary's degree of confidence is fully justified; it is the additional clause present in Assumption 2' that enables us to conclude that Gary is more justified than Barry in the example described.

Silins's argument for the more controversial sounding result is just as straightforward. This time, suppose that Gary remembers and knows that he had a banana with breakfast this morning, but he's not maximally confident that he did since he recognises that his memory, while reliable, is not infallible. So Gary slightly misjudges the force of the evidence he has, and so has a degree of confidence of .9 when his evidence actually gives the proposition a probability of 1 . Barry's evidence is that it seems to him that he had a banana with breakfast this morning, and this, we'll suppose, gives the proposition that he did an evidential probability of .9. Let's also suppose that both Gary and Barry have a degree of confidence of .9.

By Assumption 1, Barry's degree of confidence is just as it ought to be, while Gary's is not. By Assumption 2, Barry's degree of confidence is more justified than Gary's. Since Gary is in the good case and Barry is in the bad case, we can conclude that a subject in the bad case can have a more justified degree of confidence than their internal twin in the good case. ${ }^{13}$

Silins notes that not everyone will accept his first assumption, and he suggests that all that's required is the claim that 'one ought to be more confident in some propositions in the good case than in the bad case, one will sometimes underestimate one's evidence in the good case, and overestimate one's evidence in the bad case' (2005: 391). Silins doesn't expand much on the point, but presumably the idea is that even if one's degree of confidence that $\mathrm{P}$ need not match the evidential likelihood for one that $\mathrm{P}$, it's very plausible that a subject in the good case might have a lower degree of confidence than her entailing evidence justifies, and there's nothing that stops her sharing that lower degree of confidence with her internal twin who portions her confidence perfectly to her inferior evidence. Since our objections to the supervenience argument don't require us to take issue with either of Silins's original assumptions, we'll leave this alternative version of the argument aside in what follows.

\footnotetext{
12 Of course, if Gary and Barry are distinct subjects then we aren't dealing with precisely the same proposition. As Silins notes (2005: 399 n6), Barry may have to be Gary in a different world, since it's plausible that they share non-factive but de se beliefs. These complications won't matter to any of the points made in the text.

13 This is not in fact the conclusion that Silins draws from this example. More on this later.
} 
Recall how we stated the conclusion of Silins's argument above: a subject in the bad case can have a more justified degree of confidence than their internal twin in the good case. Why think that this is problematic? Silins suggests that the following thesis is plausible:

(The Bad Case is Never Better): Necessarily, if B is in the bad case and A is an internal twin of $\mathrm{B}$ in the good case, $\mathrm{B}$ is not more justified in believing $\mathrm{P}$ than A.

Notice, though, that this claim concerns justification in believing, whereas Silins's assumptions and the conclusion we have drawn from them concern the justification of degrees of confidence. Moreover, it's entirely implausible that the case Silins described is a counterexample to The Bad Case is Never Better, as stated. Recall that Gary's evidence entails that he had a banana with breakfast this morning and he's .9 confident that he did, while both the degree of confidence Barry ought to have and his actual degree of confidence is .9. It seems very odd and unmotivated to conclude from this that Barry is more justified in believing the relevant proposition than Gary is; if anything, there's some inclination to say the exactly opposite.

Our diagnosis of what goes wrong in Silins's argument is that he too freely moves back and forth between talk of the degree to which one is justified in believing $\mathrm{P}$ and the degree to which one's degree of confidence or belief that $\mathrm{P}$ is justified. ${ }^{14} \mathrm{On}$ the one hand, Silins's two assumptions, as quoted above, are explicitly put in terms of 'one's degree of confidence', and Equal Justification is stated in terms of being 'justified to degree $\mathrm{n} 1$ in believing $\mathrm{P}$ to degree $\mathrm{n} 2$ '. On the other, the crucial 'plausible' thesis The Bad Case is Never Better is put in terms of being less or more justified in believing a proposition $\mathrm{P}$.

We can bring out the difference between these two notions of doxastic justification with the following example (appropriated from Zardini 2013: 387). We have no evidence whatsoever concerning whether Barack Obama had eggs for breakfast this morning. So the evidential likelihood of both the proposition that he did have eggs and its negation is .5 for us. Our degree of confidence that he had eggs for breakfast, given our evidence, should plausibly be around .5; we should regard it as no more likely than not. In contrast, the degree to which we're justified in believing that he had eggs for breakfast is minimal. We're not at all justified in believing this; what we're justified in doing is rather suspending judgment on the matter.

This example also serves to bring out the fact that the two assumptions that the supervenience argument rests on are only plausible because they concern one's degrees of confidence, rather than the degrees to which one is justified in believing. It's plausible enough that one's degrees of confidence in a proposition ought to match its evidential probability for one, and that they are unjustified to the extent that there's a mismatch. But as the above example illustrates, the degree to which one is justified

14 This suggestion about where Silins's argument goes wrong has been made before in the literature: see Kennedy 2010: 85-6 Dunn 2012: 442 fn10. However, neither Kennedy nor Dunn develops the point in much detail, and they both prefer less general, more involved responses. In our view, those are not necessary. 
in believing a proposition typically won't match that proposition's evidential probability for one, nor is there any sense in which it ought to. ${ }^{15}$

Likewise, and this is crucial, The Bad Case is Never Better is only plausible when it is stated, as Silins in fact states it, in terms of the degree to which one has justification to believe. The subject in the bad case is doing so badly not because of how she polices her epistemic life, but because of the uncooperative nature of her external environment, and by the Evidential Externalist's lights these environmental factors bear on what evidence she has, and so on the epistemic standing of her attitudes. Given this, and given that we're currently working under the assumption that it's not transparent to one what one's evidence is, it's no surprise that she might do better than her internal twin in portioning her degree of confidence in some proposition to her evidence; that's just what Silins's examples serve to bring out. What's genuinely counterintuitive is the idea that the subject in the good case be less justified in believing a proposition than her twin in the bad case despite her superior evidence. But as we've seen, that's not the conclusion that we can derive from Silins's assumptions.

The switch from talk of degrees of confidence or belief to talk of degrees of justification to believe comes in the following passage (2005: 389):

If Evidential Externalism is true, it turns out that Gary's partial belief in B is misplaced by a wide margin, whereas Barry's partial belief in B is not misplaced at all. Indeed, Barry's confidence is causally based, in the right way, on the weaker evidence he has, whereas Gary's fails to be adequately adjusted to his stronger evidence. Since Gary underestimates his evidence, and Barry's partial belief is properly adjusted to his own evidence, the subject in the good case is less justified in believing B. ${ }^{16}$

There are a couple of different issues in this passage that need disentangling. First, there's an insinuation that Gary's confidence is not causally based, in the right way, on his evidence; it's hard to hear not the contrast in the second sentence as strongly suggesting this. But there are two problems with this. Recall, firstly, that Silins sets up his example by stipulating that Gary 'remembers and knows' that he had a banana with his breakfast this morning (2005: 389), and it's not clear that this is compatible with Gary failing to base his confidence properly on his evidence in the right way. Second, it's not clear why underestimating one's evidence should render it the case that one has failed to base one's confidence on one's evidence in the right way. Perhaps these worries are silenced when we understand 'in the right way' in the right way, but Silins doesn't say much about this.

The more important issue is that the move from facts about Gary and Barry's partial beliefs to comparisons between the degree to which each is justified in believing invites, rather than avoids, the kinds of worries that we have raised. It doesn't follow from the fact that $\mathrm{B}$ is more justified in her degree of confidence in $\mathrm{P}$ than $\mathrm{A}$, in the sense that

\footnotetext{
${ }^{15}$ Which is not to say that the latter doesn't determine the former; in the example in the text, for example, that the proposition that Obama had eggs for breakfast has an evidential probability (for us) of .5 arguably is what makes it the case that I'm justified in believing this proposition to around degree 0 .

16 Thanks to Lukas Schwengerer for drawing our attention to this passage.
} 
she has better adjusted her degree of confidence to her evidence, that $\mathrm{B}$ is more justified in believing $\mathrm{P}$ than $\mathrm{A}$ is. To go back to our earlier example, we're fully justified in having a degree of confidence of .5 that Obama had eggs this morning even though we're not justified at all in believing that he did. If Obama has entailing evidence that he had eggs this morning, but cautiously only forms a degree of confidence of .9 that he did, then his degree of confidence is further away from what it should be by Assumption 1 than ours is, and in that sense is less justified. But clearly he's not less justified in believing that he had eggs than we are.

Silins has a fallback point, which he develops in response to a different objection to his argument, but which is equally relevant given the criticism we have made of it. $\mathrm{He}$ envisages the objection to the supervenience argument that Gary's disadvantage when compared to Barry, such as it is, is a result of the superior propositional justification at his disposal, and it's hard to see how that could be problematic. In response, Silins suggests that we can see the problem for evidentialism externalism independently of the supervenience argument by noting that if it's true, 'counterintuitive assessments of beliefs in the good case turn out to be correct' (2005: 390):

Intuitively, our ordinary partial beliefs are just fine as they are: we are neither more nor less confident in our ordinary beliefs than we should be. If Evidential Externalism is true, however, we are sometimes less confident than we should be, given our evidence. Although the view does not have skeptical consequences, it implies that there are flaws in places where apparently there are none.

Silins goes on to argue that it may even be that we're typically less confident than we ought to be, if evidential externalism is true. Now, it's crucial that we realize that Silins's point is not that if evidential externalism is true then, for all we know, we're sometimes (or typically) less confident that we ought to be given our evidence. That conclusion seems to be a consequence of any account of evidence that allows that we may not always be able to recognise precisely what our evidence is and to what degree it supports a given proposition, and recall that Silins is explicitly trying to offer an argument against Evidential Externalism that does not rely on any such claim about our access to our evidence. Rather, Silins's point is that evidential externalism commits us to holding that this possibility is in fact realized, perhaps on a rather wide scale. The reason is that according to the version of evidential externalism Silins focuses on, Entailing Evidence Externalism, 'it can be easy to be in possession of evidence which obviously entails contingent propositions about the environment' (2005: 378). Given Silins's assumptions, whenever we form degrees of confidence in these contingent propositions that fall short of 1 we'll have underestimated our evidence, and so our attitudes will be less than fully justified.

It's not clear to us that there's anything much for the Evidential Externalist to worry about here. Silins's own conclusion on the matter is as follows (2005: 390):

Here the externalist might have to conclude that most of our ordinary partial beliefs are somewhat at fault, despite the fact that our ordinary beliefs seem fine as they are. 
That's probably right, but this doesn't strike us as an unbiteable bullet. Unless we think that one's evidence is transparent to one, it's hard to see why we would expect our ordinary degrees of confidence to be typically right on the money, and it's unclear why fairly small shortcomings in our degrees of confidence should be regarded as significant; Silins is surely right that we think that our degrees of confidence are just fine as they are', but it's unclear that this means that we think that they are always precisely where they should be given our evidence; rather, except in unusual cases, the discrepancies aren't big enough to matter.

\section{Evidence and Scepticism}

Finally, we turn to the topic of scepticism. As we noted in the introduction, it has often been observed that standard arguments for scepticism seem to take Evidential Internalism for granted when establishing the lemma that one's current evidence is not different to and no better than it would be were one in a suitable sceptical scenario. That suggests that one natural way to undermine such sceptical arguments is to adopt Evidential Externalism. Given that few of us want to be landed with sceptical conclusions, this seems to put Externalism at a considerable advantage. Silins contests this claim, arguing that the Evidential Internalist is at least as well placed to resist drawing sceptical conclusions as the Externalist. This section critically evaluates Silins's argument.

The sceptical reasoning in question contends that one isn't justified in believing that one isn't a handless brain in a vat. This isn't something one has a priori justification to believe, and so one's justification had better be experiential. But given Evidential Internalism, one's evidence can be no better than that possessed by one's internal twin who is a handless brain in a vat, and the kind of evidence available to one's envatted twin isn't good enough to justify one in believing that one isn't envatted oneself:

To motivate this claim, the skeptic may stress that the hypothesis entails you have the experiences you do. In particular, since the skeptical hypothesis predicts that you have an experience as of having hands, you should respond to your experience as of having hands by raising your confidence in the skeptical hypothesis, just as you should increase your confidence in any hypothesis when you discover that something it predicts is true. And given that you should raise your confidence that the skeptical hypothesis is true in response to your experience, your experience does not provide you with justification to believe that the skeptical hypothesis is false. (2005: 396)

The Evidential Externalist has a quick response they can make here, contending that one has entailing evidence lacked by one's twin in the sceptical scenario that is not entailed by the sceptical hypothesis, and which in fact entails that the sceptical hypothesis is false. So one can have justification to believe propositions about the external world, including that one is not a brain in a vat (though as Silins notes, the externalist may still owe us an account of the details of how). Assuming this response to the argument is satisfactory and that the Internalist cannot match it, Externalism seems to have an edge here. 
Let's concede, for the sake of argument, that the Externalist has something plausible to say about how one is able to have justification for one's beliefs about the external world. The apparent advantage over Evidential Internalism starts to look suspect, Silins argues, when we ask the Externalist whether one's unfortunate envatted twin also has justification for their beliefs about the external world. It's natural to think that the Externalist must deny this, since if they concede that one's twin does have justification, then they'll need to say how this is possible despite their obviously lacking the kind of entailing evidence that, according to the Externalist, we're able to possess when things go well. And it's unclear how the Externalist could have any resources for meeting that explanatory burden that aren't in principle available to the Internalist too.

Better, then, for the Evidential Externalist to deny that one's envatted twin even has justification for their beliefs about the external world. However, Silins doesn't think that the path is clear for the Externalist to deny this. First, doing so would require them to also deny the thesis Equal Justification, discussed in the previous section:

(Equal Justification): Necessarily, if $\mathrm{A}$ and $\mathrm{B}$ are internal twins, then $\mathrm{A}$ is justified to degree $n 1$ in believing $\mathrm{P}$ to degree $\mathrm{n} 2$ just in case $\mathrm{B}$ is justified to degree $\mathrm{n} 1$ in believing $\mathrm{P}$ to degree $\mathrm{n} 2$.

The Externalist will, we suspect, have few qualms about denying this thesis. However, Silins notes that the Externalist is forced to also deny the following weaker thesis:

(Outright Equal Justification): Necessarily, if $\mathrm{A}$ and $\mathrm{B}$ are internal twins, then $\mathrm{A}$ is justified simpliciter in having an outright belief in $\mathrm{P}$ just in case $\mathrm{B}$ is justified simpliciter in having an outright belief in $\mathrm{P}$.

The Externalist has a story about why this thesis is false, as we have already seen above; one's evidence in the good case entails that the sceptical hypothesis is false, while one's twin's evidence in the bad case is predicted by the sceptical hypothesis. However, Silins has offered an argument in favour of Outright Equal Justification, and so the Externalist who wants to hold that one has justification to believe one has hands while one's envatted twin does not has some work to do.

Silins's argument for Outright Equal Justification starts from the following premise:

(Suspension): Necessarily, if one lacks justification to believe $\mathrm{P}$, and one lacks justification to believe $\sim \mathrm{P}$, then one has justification to suspend judgment in $\mathrm{P}$. (Silins 2005: 392)

In fact, Silins implicitly relies on a slightly stronger thesis, to the effect that having justification to believe $\mathrm{P}$, having justification to believe $\sim \mathrm{P}$, and having justification to suspend judgment on whether $\mathrm{P}$ exhaust the options, so that if we can rule out any two of these for some subject and a proposition $\mathrm{P}$, then we can conclude that the third is the case. Let's grant Suspension even in this stronger form for the sake of argument.

Recall Gary and Barry, internal twins in a good case and a sceptical scenario respectively, both of whom believe that there is a dial in front of them. What Silins tries to show is that if Gary has justification to believe this (as the anti-sceptical 
Externalist supposes), then Barry does too. According to Silins, it can't be the case that Gary is justified in believing that there's a dial in front of Gary while his internal twin Barry is justified in believing that there is not a dial in front of Barry. Likewise, Silins holds, it can't be the case that Gary is justified in believing that there's a dial in front of Gary while Barry is justified in suspending judgment on whether there is a dial in front of Barry. Given these two claims, since Gary is justified in believing there's a dial in front of him, it follows that Barry is neither justified in believing there isn't a dial in front of Barry nor in suspending judgment on this. An application of Suspension, generalised as discussed in the previous paragraph, delivers the desired conclusion that Barry has justification to believe that there's a dial in front of him (Silins 2005: 392-3).

It seems clear where the Evidential Externalist will want to resist this argument. It's the claim that it's impossible for Gary to be justified in believing the proposition in question while his internal twin is justified in suspending judgment; as we noted earlier, following Silins himself in the passage quoted above, the Externalist has at least the beginnings of an account of why Gary's entailing evidence is good enough for him to have justification, while Barry's weaker evidence is not good enough. However, Silins offers the following point in support of this crucial claim:

[S] uppose Barry did suspend judgment in the proposition that there is a dial in front of him, despite the fact that there seems to be a dial in front of him, and despite the fact that no defeating evidence is available to him. I take it to be very implausible that Barry would be justified in suspending judgment in the matter. (2005: 392)

This point seems ineffectual against the Evidential Externalist, for at least two reasons. First, that it appears to Barry in all respects as if there's a dial in front of him and that he has no defeating evidence is just what the sceptical hypothesis predicts, leaving it very unclear how Barry could be justified in believing that there is a dial in front of him on this basis; recall once more that this is precisely the line of reasoning which Silins puts in the Externalist's mouth in the passage quoted above. Moreover, it's very natural for the Externalist to say that if Barry's evidence is predicated by the hypothesis that there's a dial in front of him, and by the hypothesis that he's a brain in a vat being presented with a mere appearance that there's a dial in front of him, then Barry is justified in suspending judgment on whether there's a dial in front of him. If there's a pretheoretical intuition to the contrary, the Externalist seems to be in a strong position to insist that it is trumped by theoretical considerations, given that the Internalist hasn't discharged the explanatory burden of explaining how it's possible for Barry to be justified in believing that there's a dial in front of him on the basis of evidence that is predicted by the hypothesis that any appearances of a dial are misleading.

Second, the Externalist can also explain away the intuition about this case that Silins identifies. The question at hand concerns whether Barry has justification to suspend judgment that there's a dial in front of him, given his evidence in the bad case. Notice, however, that Silins invites us to respond to this question by supposing that Barry in fact suspends judgment and then considering how intuitive it is to say that he's justified in so doing. This raises a number of issues, but in particular we note that the Externalist will agree that there's something very odd about Barry suspending judgment; given what Barry (wrongly) takes his evidence to be, it is natural for him to 
believe that there's a dial in front of him with considerable confidence. Putting the point in terminology familiar from the debate over the knowledge norm of assertion (e.g. Williamson 2000: 257), the Externalist will agree that it's reasonable for Barry to believe that there's a dial in front of him, and that it would be unreasonable for him to suspend judgment; but they will insist that we guard against conflating those claims with ones about what Barry has justification to believe. In inviting us to suppose that Barry in fact suspends judgment and then inviting intuitions about that scenario, Silins inadvertently encourages precisely this conflation - or so the Externalist should say.

The upshot is that the Evidential Externalist has a clear escape from Silins's dilemma. They shouldn't concede that subjects like Barry have justification for their beliefs about the external world, and they should deny Outright Equal Justification along with Equal Justification. As a result, they face the burden of explaining why a subject in Barry's evidential state is justified in suspending judgment, and that may involve denying some intuitions cherished by Internalists. But given that Barry's evidence for believing there's a dial in front of him is predicated by sceptical scenarios in which there's no dial in front of him, Externalists (not implausibly) takes their burden to be easier to discharge than that faced by the Internalist, who has to explain how Barry could be justified on the basis of such evidence. If one initially thought that the Evidential Externalist was at a genuine advantage here, we contend that nothing in Silins's discussion should change one's mind.

\section{Conclusion}

In this paper, we have offered a comprehensive reassessment of the case against Evidential Externalism and for its Internalist rival, and we have reached a very different conclusion to Silins. Silins closes his paper by writing that ' $[t]$ he overall case for Evidential Externalism might turn out to be stronger, but the case for Evidential Internalism is not weak' (2005: 398-9). We disagree; re-examining the arguments that Silins has advanced on the Internalist's behalf suggests that the case for their thesis is very weak indeed. ${ }^{17}$

\section{References}

Brown, J. (2004). Anti-Individualism and Knowledge. Cambridge, Mass.: MIT Press.

Dunn, J. (2012). Evidential Externalism. Philosophical Studies, 158, 435-55.

Farkas, K. (2008). The Subject's Point of View. Oxford: Oxford University Press.

Kallestrup, J. (2012). Semantic Externalism. Oxon: Routledge.

Kennedy, M. (2010). Naïve Realism and Experiential Evidence. Proceedings of the Aristotelian Society, 110, 77-109.

\footnotetext{
17 We would like to thank Matt Jope and Lukas Schwengerer for helpful discussion, and Veli Mitova for suggestions that led to improvements. Parts of this paper were presented at The Factive Turn in Epistemology at the University of Vienna and at the second Fallibility, Rational Belief, and Knowledge workshop at the University of Barcelona; we are grateful to all of the participants at those events for their feedback. Aidan McGlynn would like to gratefully acknowledge support from the FARBEK project FFI2013-45968-P, funded by the Spanish Ministry of Economy (MINECO).
} 
Littlejohn, G. (2012). Fustification and the Truth-Connection. Cambridge: Cambridge University Press.

McGlynn, A. (2014). Knowledge First? Basingstoke: Palgrave Macmillan.

McKinsey, M. (1991). Anti-Individualism and Privileged Access. Analysis, 51, 9-16.

Nuccetelli, S. (1999). What Anti-Individualists Cannot Know A Priori. Analysis, 59, $48-51$.

Pritchard, D. (2012). Epistemological Disjunctivism. Oxford: Oxford University Press.

Pritchard, D. (2011). Evidentialism, Internalism, Disjunctivism. In T. Dougherty (Ed.), Evidentialism and its Discontents (pp. 235-53). Oxford: Oxford University Press.

Silins, N. (2005). Deception and Evidence. Philosophical Perspectives, 19, 375-404.

Williamson, T. (2000). Knowledge and its Limits. Oxford: Oxford University Press.

Zardini, E. (2013). Luminosity and Vagueness. Dialectica, 66, 375-410. 